\title{
Eating behaviour styles and their association with sex, BMI and energy intake in Irish teens from the National Teens' Food Survey II
}

\author{
A.N. Daly ${ }^{1}$, E.J. O’Sullivan ${ }^{1}$, B.A. McNulty ${ }^{2}$, J. Walton ${ }^{3}$ and J.M. Kearney ${ }^{1}$ \\ ${ }^{1}$ School of Biological \& Health Sciences, Technological University Dublin, Dublin, Ireland, \\ ${ }^{2} U C D$ Institute of Food and Health, University College Dublin, Dublin, Ireland and \\ ${ }^{3}$ Department of Biological Sciences, Munster Technological University, Cork, Ireland
}

Eating behaviours vary by sex, age and BMI status, and different eating behaviour styles are associated with varying dietary intakes ${ }^{(1)}$. This study aims to determine factors associated with the eating behaviours of Irish teens, using data from the recent National Teens' Food Consumption Survey II (NTFSII 2019/20, $\mathrm{n}=428, \mathrm{M} / \mathrm{F}: 212 / 216)^{(2)}$.

The Three Factor Eating Questionnaire (TFEQ-r18) contains 18 items, making up 3 scales: Cognitive Restraint (CR, 6 items), Emotional Eating (EE, 3 items), Uncontrolled Eating (UE, 9 items) $)^{(3)}$.

Converted scores range from $0-100$, indicating the proportional contribution of each eating behaviour style, and are calculated using the equation S-L/Rs x100 ( $\mathrm{S}=$ sum of scale scores, $\mathrm{L}=$ lowest possible score, $\mathrm{Rs}=$ possible score range $)^{(3)}$.

Descriptive statistics, independent samples t-tests and Pearson correlations were run to test associations between the three TFEQ-r18 scales and age, sex, BMI, Physical Activity (PA), weight perception and dietary variables, including total daily energy intake (kcal) and daily fat, protein and carbohydrate intakes (as\% Total Energy).

Mean(SD) scores among the whole group were $\mathrm{CR}=28.25(17.62), \mathrm{EE}=25.03(27.77)$, $\mathrm{UE}=38.84(18.73)$. Females scored higher than males on CR (32.20(18,85), 24.97(15.64)) and EE (34.51(29.84), 15.20(21.13), both $P<0.001)$. Older teens scored higher than younger teens on EE (29.30(28.76), 21.45(26.20)) and UE (41.65(17.39), 36.76(19.16), both $P<0.01)$. CR was positively correlated with BMI $(r=0.25)$ and PA $(r=0.11$, both $P<0.001)$. EE was positively correlated with age $(r=0.19)$ and BMI $(r=0.21$, both $P<0.001)$, and UE was positively correlated with age $(r=0.12, P=0.01)$. Teens who perceived themselves as overweight scored higher on both $\mathrm{CR}$ and EE compared with those who perceived themselves as either the correct weight or underweight (all $P<0.001)$. Daily energy intake was negatively correlated with CR $(r=-0.22)$ and EE $(r=-0.19)$ and positively correlated with UE $(r=0.16$, all $P<0.001)$.

The predominant eating behaviour style for Irish teens is UE, which is eating more than intended based on hunger, sensory factors, or being physically near food. In general, levels of CR and EE are lower in this Irish teen cohort, but both restrained and emotional eating are higher in girls, those with a higher BMI, with a negative weight perception, and with lower energy intakes. Teens with a higher BMI show higher levels of CR and EE, but the direction of causality is unclear - does BMI change the eating behaviour or does the eating behaviour increase BMI? However, the associations between weight perception, dietary intake and eating behaviour styles suggest that, independent of measured BMI, teens who perceive their weight to be too high may be more likely to change their eating and activity habits because of this. This information could help inform healthy eating messages to teens based on motivating factors for diet habits, getting the balance right to prevent both overeating and disordered eating habits.

\section{Acknowledgments}

The author would like to acknowledge funding from the Department of Agriculture, Food and the Marine, Ireland, and the IUNA network.

\section{References}

1. Daly AN, O'Sullivan EJ, Walton J et al. (2020) Public Health Nutr, 1-9.

2. The Irish Universities Alliance (2021), NTFS II: Summary Report [Available at: www.iuna.net]

3. De Lauzon B, Romon M, Deschamps V, et al. (2004) J. Nutr 134, 2372-2380. 